\title{
Speed Control of field oriented induction motor using DsPIC Controller
}

\author{
R.Senthil Kumar, Assistant professor, Aakash Mishra, student, Mohammad \\ Asfar, student, Mohammad Shahzad, student \\ ${ }^{1,2,3,4}$ SRM University, Chennai
}

\begin{abstract}
The paper entitled "Control of field oriented induction machine using dsPIC Controller" review for field oriented control (FOC) induction machine. In this paper Closed loop control of adjustable speed drive is presented. DSPIC30F4011 Controller is a new platform for motor control application. In recent years, the use of ASD with advanced control technique is important for automation process for the application of industrial drives. This controller based, PWM-output, variable frequency drives provide the user with a tremendous variety of features and functions which allow accurate control and monitoring in nearly every 3-phase induction motor application. In this project, a proxy sensor or IR sensor is used to measure the speed of the motor and its given to the controller. The controller generates the pulses to drive the motor.
\end{abstract}

Keywords: dsPIC, Induction motor, field oriented control

\section{Introduction}

As the induction motor is one of the most popular motor in the field of commercial and industrial fields due to its simple construction but due to its complexity of torque speed curve where there is no decoupling between the field power and the armature power as DC motor. The objective of the field oriented control technique of the induction machine is to treat it as a DC machine where the armature current and the field flux are two independent variables controlling the developed electromagnetic torque such that

$\mathrm{T}=\mathrm{k}_{\mathrm{t}} \mathrm{I}_{\mathrm{f}} \mathrm{Ia}$

where $\mathrm{T}$ :is the developed torque

$\mathrm{I}_{\mathrm{f}}$ : is the field current

$\mathrm{I}_{\mathrm{a}}:$ is the armature current

$\mathrm{K}_{\mathrm{t}}$ : is the machine constant

Therefore, the torque can be controlled either by increasing the $I_{a}$ or $I_{f}$ and also the speed can be increased by increasing a I or reducing If (field weakening). This technique of control the DC machine can be applied to AC machines by decomposing the machine currents into two orthogonal components:

$\mathrm{I}_{\mathrm{ds}}($ the direct axis component of the stator current) which represent the field current in the DC machine and $\mathrm{I}_{\mathrm{qs}}$ (the quadrature axis component of the statorcurrent) which is responsible for torque production. Thedeveloped electromagnetic torque is given by:

$\mathrm{T}=\mathrm{K}_{\mathrm{t}} \mathrm{I}_{\mathrm{qs}} \mathrm{I}_{\mathrm{ds}}$

and the control will be imitated as in DC machine

\section{Hardware Block Diagram}

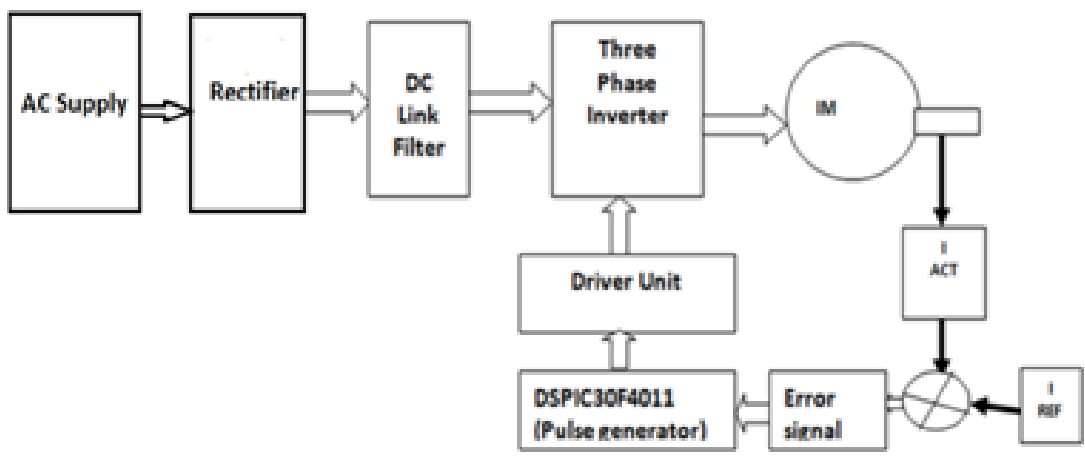

Fig.1 
A single phase ac supply is given to the circuit which passes to the rectifier in order to convert it to dc output voltage. The output is then filtered using a capacitor setup to remove the harmonics. The three phase inverter consists of MOSFETs and diodes. Pulses are given to the three phase inverter by the dsPIC controller. The closed loop circuit mainly comprises of an error signal generated by the difference between output speed of the motor and input reference speed set up by the operator. This error signal is then minimized in the dsPIC Controller and pulses are generated which are given to the inverter to generate output accordingly.

$\mathrm{a}=\operatorname{int}\left(\left(\mathrm{V}_{\mathrm{qs}}-\mathrm{I}_{\mathrm{qs}} \mathrm{R}\right) \mathrm{dt}\right)$

\section{Mathematical Modelling}

$\mathrm{b}=\operatorname{int}\left(\left(\mathrm{V}_{\mathrm{ds}}-\mathrm{I}_{\mathrm{ds}} \mathrm{R}\right) \mathrm{dt}\right)$

Torque:

$\mathrm{T}=-\mathrm{a} * \mathrm{I}_{\mathrm{ds}}+\mathrm{b} * \mathrm{I}_{\mathrm{qs}}$

Flux:

$q=\operatorname{mag}(a+i b)$

Angle:

theta $=\operatorname{angle}(a+i b)$

abc to dq:

$\mathrm{V}_{\mathrm{q}}=2 / 3\left(\mathrm{~V}_{\mathrm{a}}-1 / 2 \mathrm{~V}_{\mathrm{b}}-1 / 2 \mathrm{~V}_{\mathrm{c}}\right)$

$\mathrm{V}_{\mathrm{d}}=2 / 3\left(-\operatorname{sqrt}(3) / 2 \mathrm{~V}_{\mathrm{b}}+\operatorname{sqrt}(3) / 2 \mathrm{~V}_{\mathrm{c}}\right)(7)$

$\mathrm{I}_{\mathrm{q}}=2 / 3\left(\mathrm{I}_{\mathrm{a}}-1 / 2 \mathrm{I}_{\mathrm{b}}-1 / 2 \mathrm{I}_{\mathrm{c}}\right)$

$\mathrm{I}_{\mathrm{d}}=2 / 3\left(-\operatorname{sqrt}(3) / 2 \mathrm{I}_{\mathrm{b}}+\operatorname{sqrt}(3) / 2 \mathrm{I}_{\mathrm{c}}\right)$

abc to dq conversion:

$\mathrm{I}_{\mathrm{a}}=-\mathrm{V}_{\mathrm{q}} * \sin ($ theta $)+\mathrm{V}_{\mathrm{d}} * \cos ($ theta)

$\mathrm{I}_{\mathrm{b}}=(-\cos ($ theta $)+1.7320508 * \sin ($ theta $))(11) * \mathrm{~V}_{\mathrm{d}} * 0.5+(\sin ($ theta $)+1.7320508 * \cos ($ theta $)) * \mathrm{~V}_{\mathrm{q}} * 0.5$

Motor Parameters

$\operatorname{Rr}=9.295 \mathrm{e}-3$;

$\mathrm{Lr}=0.3027 \mathrm{e}-3$;

Ts $=20 \mathrm{e}-6$;

$\mathrm{Lm}=10.46 \mathrm{e}-3$;

$\mathrm{fc}=16$;

$\mathrm{kp}=100$;

$\mathrm{ki}=30$;

$\mathrm{p}=2$;

Tvect=20e-6;

\section{Main Block:}

\section{Simulation Blocks}

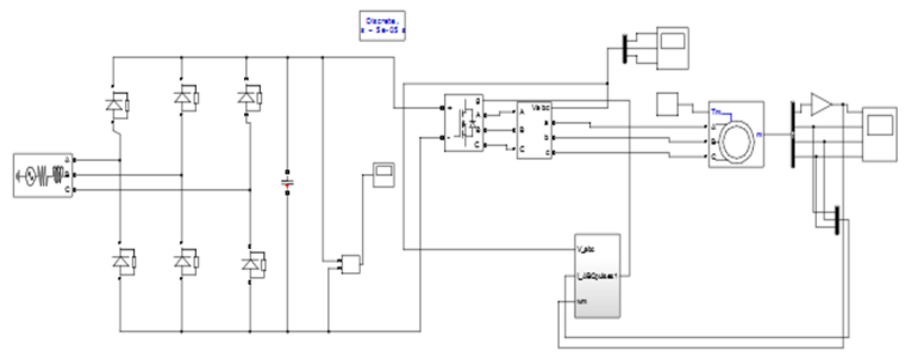

Fig.2

A 3 phase input of $460 \mathrm{v}$ is given to the system which is then converted to dc output using rectifier circuit which is used as source of constant supply for the MOSFET. 


\section{Subsystem:}

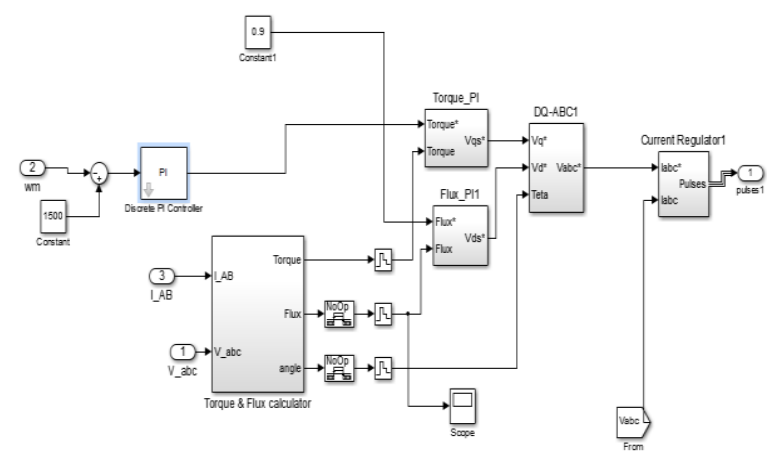

Fig.3

The error signal is generated depending on the reference speed and output speed, which is then used to generate $V_{q}$ and $V_{d}$ which is eventually used to generate current pulses which is used as input to the MOSFET 3 phase inverter.

\section{Torque and flux generation:}

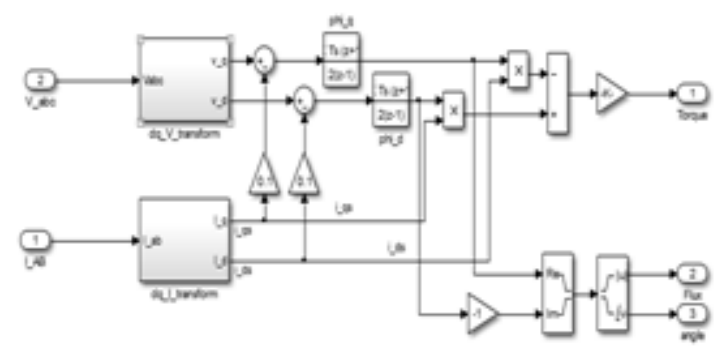

Fig.4

The stator input voltages and currents are converted into the quadrature and direct axis components. The Torque and Flux components are calculated by using the formulas (3) and (4) respectively

\section{dq_V_Transform and dq_I_Transform:}

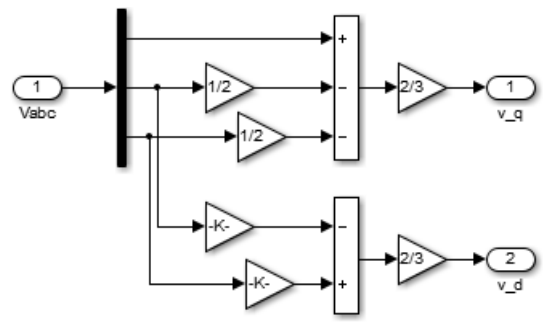

Fig.5

The formulas used in order to construct this subsystem are the formulaes (6),(7),(8) and (9). This system is used to convert the three phase ac voltage and currents into their quadrature and direct axis components.

DQ-ABC1:

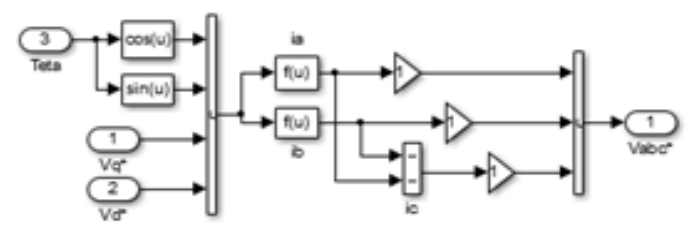

Fig.6

The calculated quadrature and direct axis components are then again converted into the three phase abc components.

The formulas used are (10) and (11) respectively. 


\section{Current Regulator:}

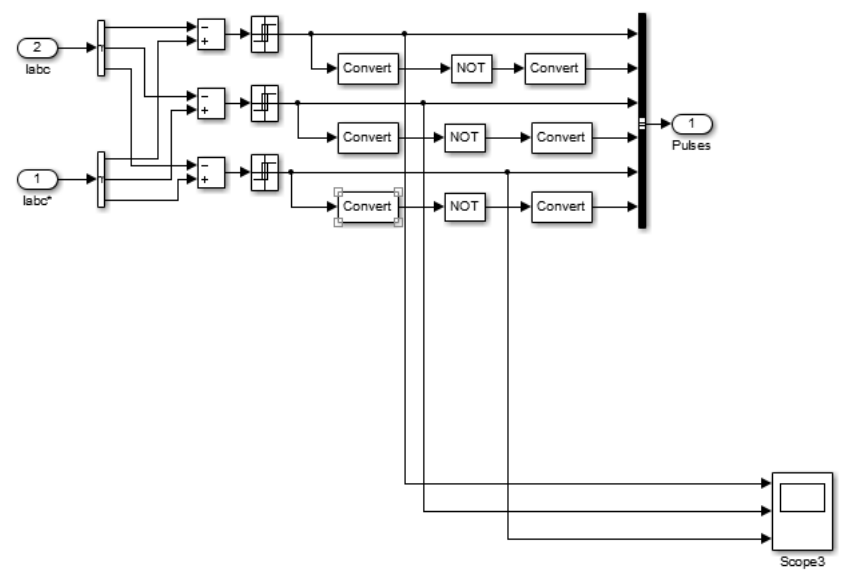

Fig.7

The current regulator creates the current pulses which serve the gate of the inverter

The inverter as shown in Fig.1 is then used to generate the input stator voltage $\mathrm{V}_{\mathrm{abc}}$ for the induction motor. The output of this goes to the inverter in the main block as shown in the Fig.2

\section{Simulation results}

Speed:

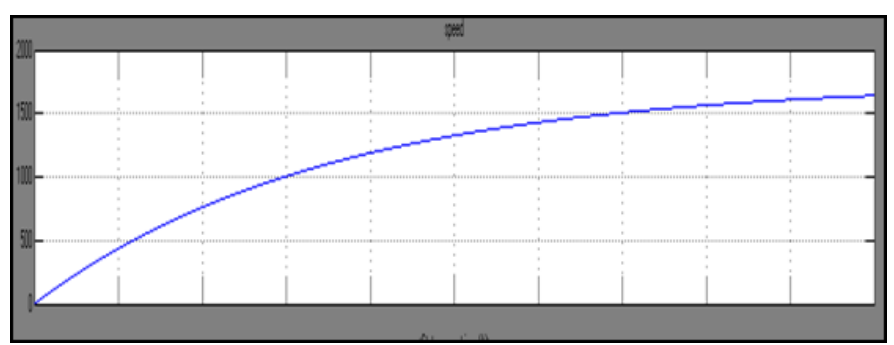

Fig.8

The speed when reference speed is set at $1500 \mathrm{rpm}$

Stator currents:

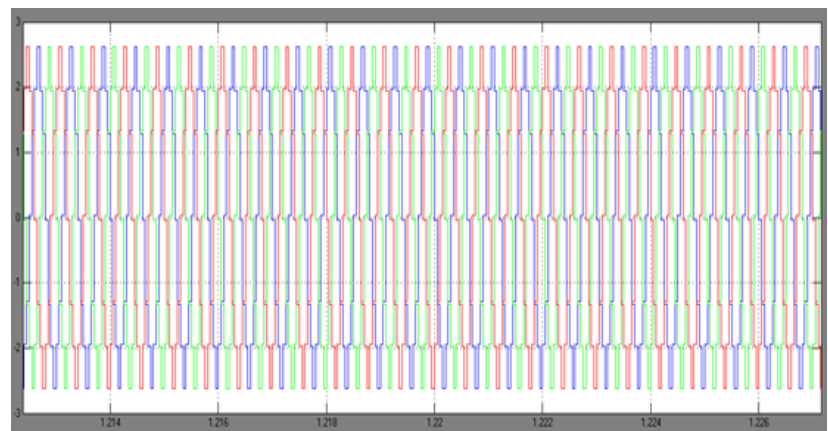

Fig.9

3 Phase stator current input to the induction motor

Current pulses:

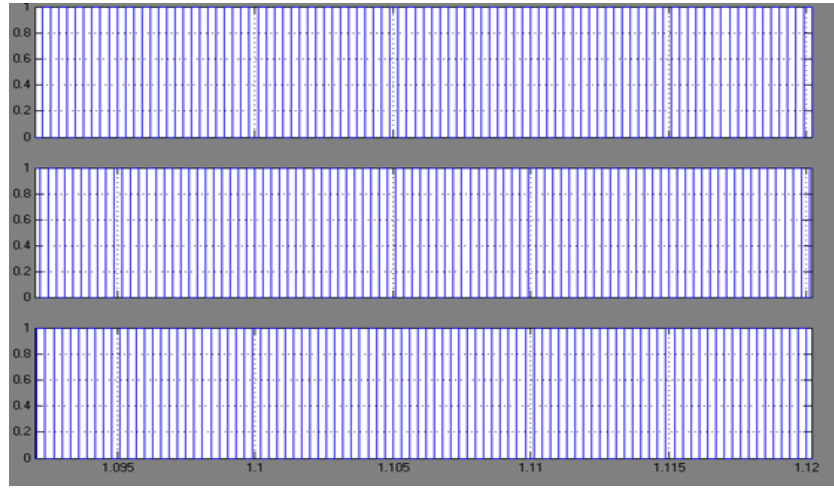

Fig.10 
The current pulses created which serve as input to the 3 phase inverter

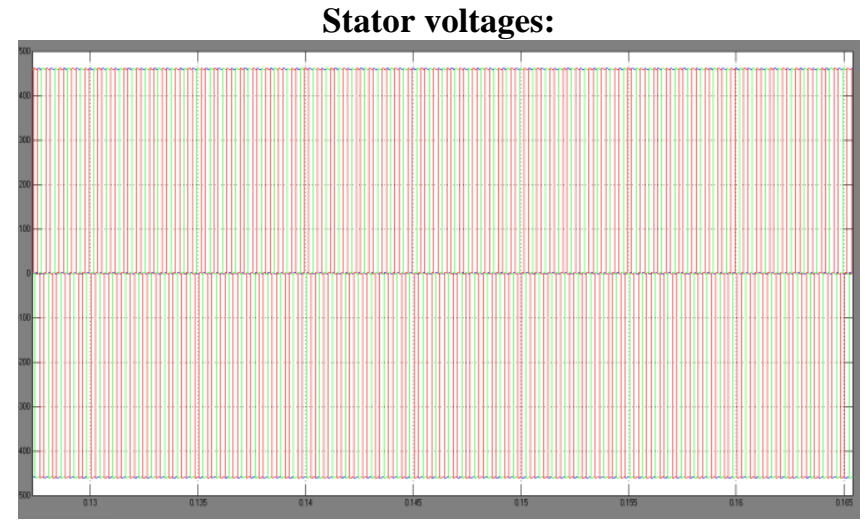

Fig.11

The 3 phase input voltages created by the Inverter depending upon the input current pulses given to the inverter.

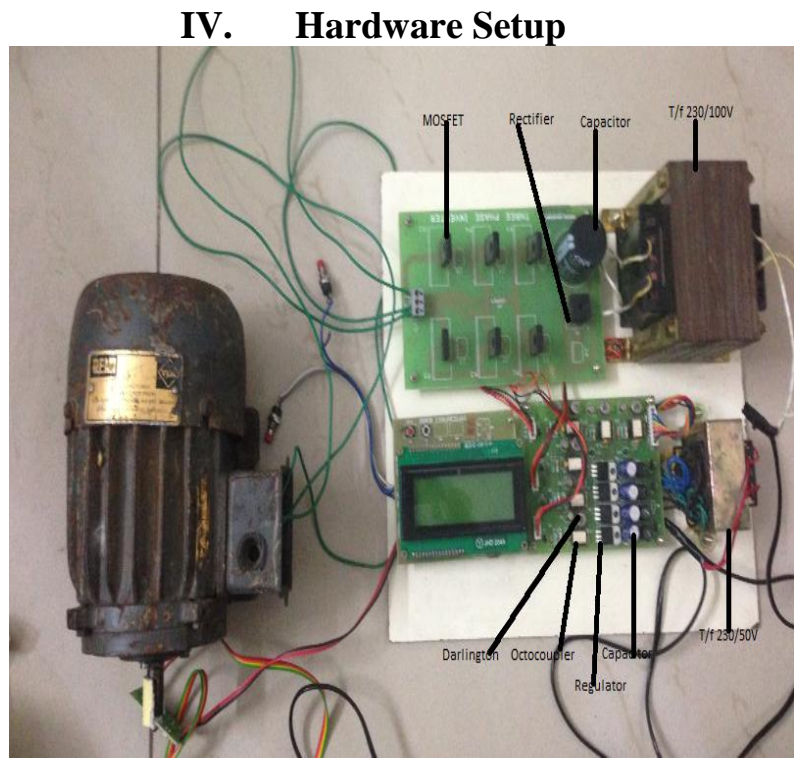

Fig.12

A 3 phase inverter has 6 MOSFET switches that are controlled in order to generate an AC output from the DC input. The power inverter has 6 switches that are controlled in order to generate an AC output from the DC input. PWM signals generated from the microcontroller control these 6 gate pulses. The phase voltage is determined by the duty cycle of the PWM signals. In time, a maximum of three switches will be on, either one upper and two lower switches, or two upper and one lower switch. When the switches are on, current flows from the DC bus to the motor winding. The PWM signals generated from the dsPIC Controller depends upon the input reference speed set by the user and the output of the induction motor.

\section{Conclusion}

In this project control of field oriented induction motor is discussed and the same is implemented in the MATLAB simulation.The output of speed, stator currents, voltage input to the motor and current pulses input to the gate are obtained. Speed control of induction motor is also done in the hardware using dsPIC microcontroller for better response time of the output.

\section{Future work}

The response time of the setup is an issue that requires attention and can be made better by using better quality controllers and more efficient instruments. 


\section{References}

[1]. Seungdeog Choi, Student Member, IEEE, Bilal Akin, Member, IEEE,Mina M. Rahimian, Student Member, IEEE, and Hamid A. Toliyat, Fellow, IEEE Implementation of a Fault-Diagnosis Algorithm for Induction Machines Based on Advanced Digital-SignalProcessing Techniques IEEE TRANSACTIONS ON INDUSTRIAL ELECTRONICS, VOL. 58, NO. 3, MARCH 2011

[2]. David M. Reed Member, IEEE, MIT Lincoln Laboratory Heath F. Hofmann Member, IEEE, University of Michigan - Ann Arbor Direct Field-Oriented Control of an Induction Machine using an Adaptive Rotor Resistance Estimator

[3]. HeberttSira-Ramírez, Senior Member, IEEE, Felipe González-Montañez,John Alexander Cortés-Romero, and Alberto LuvianoJuárez A Robust Linear Field-Oriented Voltage Control for the Induction Motor: Experimental Results IEEE TRANSACTIONS ON INDUSTRIAL ELECTRONICS, VOL. 60, NO. 8, AUGUST 2013

[4]. Ahmed. F. Abd El-Halim, Control and Instrumentationi Sidi Kerier Petrochemical Alexandria, Egypt, Mohamed . M. Abdulla, MIEEE, Ibrahim. F. El-Arabawy, SMIEEE Practical Methodology of Control and Protection of Field Oriented Induction Machine Using Digital Signal Processing ICCTA 2012, 13-15 October 2012, Alexandria, Egypt

[5]. Anno Yoo, Chanook Hong, Basic Technology R\&D Center LSIS Anyang, Korea, Jung-Ik Ha, School of Electrical \& Computer Engineering, Seoul National University, Seoul, Korea On-line Rotor Time Constant Estimation for Indirect Field Oriented Induction Machine

[6]. [6] D. J. TILAK SIYAMBAlAPITIYA, STUDENT MEMBER, IEEE PETER G. McLAREN, MEMBER, IEEE, A Rotor Condition Monitor for Squirrel-Cage Induction Machine IEEE TRANSACTIONS ON INDUSTRY APPLICATIONS. VOL. IA-23 NO. 2. MARCH,APRIL

[7]. Shahin Hedayati Kia, Humberto Henao, Senior Member, IEEE Gérard-André Capolino, Fellow, IEEE Diagnosis of Broken-Bar Fault in Induction Machine Using Discrete Wavelet Transform Without Slip Estimation 